\title{
Deformation of a cell monolayer due to osmotic treatment: a case study of onion scale epidermis ${ }^{1}$
}

\author{
Sandra Natonik-Białoń, Dorota Borowska-Wykręt, Gabriella Mosca, Michał Grelowski, \\ Roman Wrzalik, Richard S. Smith, and Dorota Kwiatkowska
}

\begin{abstract}
We performed a combination of experiments and mechanical simulations to assess the importance of cell geometry and wall structure in tissue and cell mechanics. Osmotic treatments combined with live imaging were used to quantify deformations at the tissue, cellular, and subcellular levels. We used the adaxial epidermis of onion scale as a model system. We found that the osmotically induced surface strain in onion is small because outer periclinal walls are thick and stiff, requiring bending stiffness to be considered in our mechanical models. As expected, the mechanical behaviors of the tissue and its component cells are related. Upon changes in internal pressure, cells embedded in the tissue undergo deformation that is different from isolated cells, while the tissue undergoes a somewhat counterintuitive deformation, e.g., shrinking upon pressurization, that depends on cell geometry. At the subcellular level, the amount of deformation and its anisotropy vary within the walls of individual cells, and are affected by the cell shape and vicinity of three-way wall junctions. When the turgor pressure is lost, the protoplast-facing wall surface wrinkles due to buckling, with the pattern of wrinkles depending on the strain anisotropy and the local wall geometry.
\end{abstract}

Key words: cell wall buckling, cell wall curvature and strain, mechanical model, onion epidermis, osmotic treatment.

Résumé : Les auteurs ont réalisé une combinaison d'expériences et de simulations mécaniques pour évaluer l'importance de la géométrie et de la structure de la paroi des cellules dans la mécanique cellulaire et tissulaire. Des traitements osmotiques combinés à l'imagerie ven temps réel ont été utilisés pour quantifier les déformations aux niveaux tissulaire, cellulaire et subcellulaire. Ils ont utilisé, comme système modèle, l'épiderme adaxial de l'écaille de l'oignon. Ils ont trouvé que la déformation de la surface induite de manière osmotique chez l'oignon est petite, car les parois externes périclinales sont épaisses et rigides, nécessitant une rigidité mécanique pour être prises en compte dans leurs modèles mécaniques. Comme prévu, les comportements mécaniques du tissu et de ses cellules constituantes sont reliés. En fonction des changements de pression interne, les cellules intégrées dans le tissu subissent une déformation différente de celle des cellules isolées, alors que le tissu subit une déformation quelque peu contre-intuitive, c'est-à-dire un rétrécissement en fonction de la pressurisation qui dépend de la géométrie cellulaire. À l'échelle subcellulaire, l'amplitude de la déformation et son anisotropie varient à l'intérieur des parois des cellules individuelles et elles sont affectées par la forme de la cellule et la proximité de jonctions tripartites de la paroi. Lorsque la pression de la turgescence est perdue, la surface de la paroi qui fait face au protoplaste se ride à cause de la déformation, le patron des rides dépendant de l'anisotropie de la déformation et la géométrie locale de la paroi.

Mots-clés : déformation de la paroi cellulaire, déformation et courbure de la paroi cellulaire, modèle mécanique, épiderme de l'oignon, traitement osmotique.

Received 7 February 2019. Accepted 25 June 2019.

S. Natonik-Białoń,* D. Borowska-Wykręt,* M. Grelowski, and D. Kwiatkowska. Department of Biophysics and Morphogenesis of Plants, Faculty of Biology and Environment Protection, University of Silesia in Katowice, Jagiellońska 28, 40-032 Katowice, Poland. G. Mosca. Max Planck Institute for Plant Breeding Research, Carl-von-Linne-Weg 10, D-50829 Cologne, Germany, and Department of Plant and Microbial Biology, University of Zurich, Zurich, Switzerland.

R. Wrzalik. Silesian Center for Education and Interdisciplinary Research, 75 Pułku Piechoty 1A, 41-500 Chorzów, Poland, and A. Chełkowski Institute of Physics, University of Silesia in Katowice, Uniwersytecka 4, 40-007 Katowice, Poland.

R.S. Smith. Max Planck Institute for Plant Breeding Research, Carl-von-Linne-Weg 10, D-50829 Cologne, Germany.

Corresponding author: Dorota Borowska-Wykręt (email: dorota.borowska-wykret@us.edu.pl).

*These authors contributed equally.

${ }^{1}$ This Article is part of a Special Issue from the 9th International Plant Biomechanics Conference (9-14 August 2018, McGill University). Copyright remains with the author(s) or their institution(s). Permission for reuse (free in most cases) can be obtained from RightsLink. 


\section{Introduction}

Walls of living plant cells are under considerable stress that originates from the turgor pressure within, which is a result of the higher osmotic potential in the protoplast compared to the external medium. In some organs this stress can transfer from tissue to tissue, resulting in tissue stresses (Hejnowicz 2011). The stress is primarily tensile, and results in elastic (reversible) wall strain. The stress can be removed from the walls by treatment with a hypertonic solution (osmotic treatment), although in some tissues residual stresses can remain after plasmolysis. As a result of this treatment the turgor drops, cell volume decreases, and the wall strain is reversed, i.e., the elastically stretched walls shrink. The extent of shrinking decreases with increasing thickness or stiffness of walls (Zimmermann 1978), and the shrinking can be high in meristematic tissue built of cells that have relatively thin and "soft" (elastic) walls (Kierzkowski et al. 2012), compared with more mature tissue. Osmotic treatment leads not only to the wall shrinking, but also to changes in the wall surface curvature (Routier-Kierzkowska et al. 2012). Moreover, in cells with rather thick walls, the removal of tensile stress leads to wrinkling of the wall surface that faces the protoplast. This is a manifestation of buckling of the youngest layers of the wall that results from a gradient in the elastic strain of wall layers, the values of which decreases in the direction toward the protoplast (Hejnowicz and Borowska-Wykręt 2005; Lipowczan et al. 2018).

The overall wall deformation due to the osmotic treatment, including the curvature changes and the surface strain, can be predicted for isolated cells with simple shapes such as a cylinder or sphere, and known wall stiffness (Hejnowicz 2011; Weber et al. 2015). The problem becomes more complex when a cell is embedded in tissue and its shape is irregular (Mosca et al. 2017). In this context, the inner (adaxial) epidermis of onion scale is an example of a simple tissue. Its elongated cells, the walls of which are generally straight, form a monolayer. This monolayer is easy to isolate, and was used as a model tissue in many experiments (see for example Oparka 1994; Ng et al. 2000; Wei et al. 2001; Suslov et al. 2009; Routier-Kierzkowska et al. 2012).

Our objective was to characterize the deformation of the monolayer-like tissue and walls of its cells that takes place upon osmotic treatment and to explore the relationships between the mechanics of tissue and component cells. To assess the importance of local geometry and cell wall structure in tissue and cell mechanics, we quantified deformation at the tissue, cellular and subcellular levels, using a combination of various experimental methods and realistic mechanical simulations.

\section{Materials and methods}

Plant material

We used scales (fleshy storage leaves) of mature yellow onion (Allium cepa) obtained from a local grocery store. Strips of epidermis were isolated from the equatorial region of inner (adaxial) surface of scales. The outer nondried fleshy scales (from first to fourth counting from the onion surface after removal of papery scarious scales) were used for experiments.

\section{Strain measurements at tissue scale using light microscopy}

Prior to strain measurements we assessed the osmoticum concentration that causes apparent plasmolysis in cells of isolated epidermal strips. Examining the strips treated with a sequence of mannitol solutions of increasing concentration (with step of $0.1 \mathrm{~mol} / \mathrm{L}$ ), we found that the lowest concentration at which all the cells were plasmolysed (all of the protoplasts were considerably detached at tips of cells; Supplementary data, Fig. S1A ${ }^{2}$ ) was $0.7 \mathrm{~mol} / \mathrm{L}$ mannitol. The solution of $0.38 \mathrm{~mol} / \mathrm{L} \mathrm{NaCl}$, which has an osmolality similar to $0.7 \mathrm{~mol} / \mathrm{L}$ mannitol, also caused the apparent plasmolysis. Strain was measured in isolated epidermal strips, $5 \mathrm{~mm} \times 5 \mathrm{~mm}$, which were first immersed in deionized water for $5 \mathrm{~min}$. Afterwards, each strip was covered with a glass coverslip, and the first image was taken using light microscopy (Nikon Eclipse 80i). Next, the sample was treated with $0.7 \mathrm{~mol} / \mathrm{L}$ mannitol or $0.38 \mathrm{~mol} / \mathrm{L} \mathrm{NaCl}$. The second image was taken when plasmolysis was visible in cells of the central part of the strip (after 10-15 min). In both of the images, the same three-way cell wall junctions were recognized such that they defined line segments (1.1-2.0 $\mathrm{mm}$ long) the orientation of which was either parallel (longitudinal direction) or orthogonal (transverse direction) to the long axes of the epidermal cells [Fig. 1A (A1)]. The segments encompassed 2-5 cells in the longitudinal direction or 9-19 cells in the transverse direction. Segment lengths were measured in both images using CorelDRAW X6 (Corel Corp.). Unidirectional deformations due to osmotic treatment were then computed for both directions as follows: $\left(L_{p}-L_{t}\right) / L_{t}$ (in percent), where $L_{t}$ is the segment length in turgid tissue, and $L_{p}$ is the segment length in plasmolyzed tissue. The negative strain values thus refer to tissue shrinking, whereas the positive values refer to extension in a given direction. In the same images, the surface area of polygons defined by cell-wall junctions was measured, which covered a large portion of the visible strip surface [Fig. 1A (A1)]. Areal strain due to osmotic treatment was then computed for the strips as: $\left(A_{\mathrm{p}}-A_{\mathrm{t}}\right) / A_{\mathrm{t}}$ (in percent), where $A_{\mathrm{t}}$ is the surface area of the polygon in a turgid strip, and $A_{\mathrm{p}}$ is the surface area in the plasmolysed strip. Nine tissue strips treated with

\footnotetext{
${ }^{2}$ Supplementary data are available with the article through the journal Web site at http://nrcresearchpress.com/doi/suppl/10.1139/cjb-
} 2019-0027. 
Fig. 1. Empirical analyses at the tissue and cellular scale. (A) Diagram showing the parameters used to assess the osmotically induced tissue and cell deformation. (A1) At the tissue scale, unidirectional deformations in longitudinal and transverse directions are assessed by comparison of lengths of line segments (black lines with arrows) defined by wall junctions, which are recognized in the epidermal strip in turgid and plasmolysed states. For the same strip, the surface area of a polygon (outlined in black), which covers a large portion of the strip, is compared between the turgid and plasmolysed states to assess the tissue areal strain. (A2-A4) The cellular scale. (A2) The volume of a cell extracted from confocal microscopy images of turgid and plasmolysed strips, is used to compute the volumetric strain. (A3) The surface area of the outer periclinal wall, assessed from the same confocal images, is used to compute the areal strain of the wall. The wall shape is quantified by curvature of the surface reconstructed from in vivo replica images. (A4) Areal strain is also computed for cell outlines, i.e., polygons (black outline) defined by wall junctions (black dots), which are recognized for the same cells in turgid and plasmolysed strips. (B) Analyses of the outer periclinal cell wall. (B1) Periclinal walls of cells from the plasmolysed strip are analyzed using Nomarski microscopy to visualize wrinkles that form on the protoplast facing surface of the wall (B2). (B3) The wall observed from the protoplast side is analyzed using polarized light microscopy to assess the net orientation of cellulose microfibrils (B3). Patches of the protoplast-facing wall surface (B4) are examined using atomic force microscopy to visualize the microfibril arrangement in the youngest wall layer.
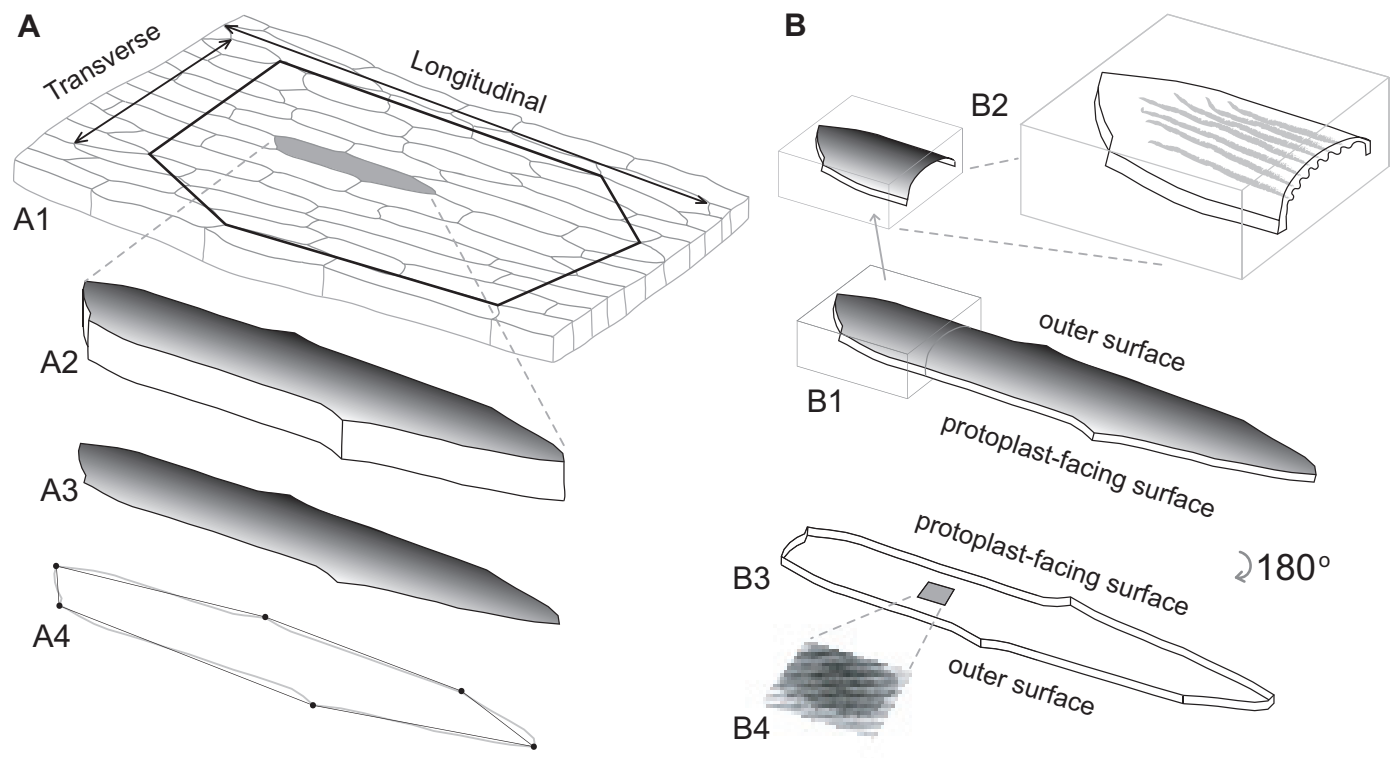

each osmoticum were examined, and 3-6 line segments and a single polygon were followed for each strip.

\section{In vivo confocal microscopy and strain measurement at the cellular scale}

Strips of epidermis $5 \mathrm{~mm} \times 5 \mathrm{~mm}$ with a few layers of underlying parenchyma cells (included to keep the epidermis viable for a longer time) were isolated and treated with $0.1 \%$ solution of propidium iodide in deionized water for 10-15 min to stain the cell walls (Hamant et al. 2014). They were then gently rinsed in deionized water, and placed in water between two coverslips. The epidermal cells were then scanned using an inverted confocal laser scanning microscope (Olympus FV1000) equipped with a UPlanFl $10 \times / 0.3$ objective, and a laser emitting at a wavelength of $543 \mathrm{~nm}$. Stacks of sections taken at 1.15 or $1.5 \mu \mathrm{m}$ (no zoom or frame averaging), were collected at the laser power adjusted such that the images were oversaturated to improve further analysis. Next, the samples were plasmolysed in $0.38 \mathrm{~mol} / \mathrm{L} \mathrm{NaCl}$ for $10 \mathrm{~min}$ and scanned again. The stacks of images were analyzed using the MorphoGraphX software (de Reuille et al. 2015) and changes in area (the strain in area of outer periclinal cell walls) were computed as: $\left(A_{\mathrm{p}}-A_{\mathrm{t}}\right) / A_{\mathrm{t}}$ (in percent), where $A_{\mathrm{t}}$ is surface area of the wall in turgid tissue, and $A_{\mathrm{p}}$ is surface area of the wall in plasmolyzed tissue. Volumetric strain was computed similarly. Three samples, each comprising 27-45 cells, were analyzed in this way.

\section{In vivo replicas, curvature assessment and strain} measurement at the cellular scale

Scale fragments, $10 \mathrm{~mm} \times 10 \mathrm{~mm}$, were isolated using a razor blade, and the first silicone polymer replica was taken from the surface of inner epidermis as previously described (Kwiatkowska and Burian 2014). Then, the whole scale fragment was immersed in the plasmolysing solution for $20 \mathrm{~min}$. Because the polymer becomes sticky in the presence of mannitol, we used $\mathrm{NaCl}$ solutions for replicas. The samples were treated with either $0.2 \mathrm{~mol} / \mathrm{L}$ $\mathrm{NaCl}$, causing incipient plasmolysis (based on examination of plasmolysis in the isolated epidermal strips treated with $\mathrm{NaCl}$ solutions of increasing concentration; 
Fig. 2. Deformation of adaxial onion scale epidermis due to osmotic treatment. Negative strain values indicate shrinking. (A) Tissue scale measurements: unidirectional deformation in the longitudinal and transverse directions for samples treated with different osmotica. Dots, indicate the mean value for each sample; whiskers, indicate the standard error of the mean. The standard deviation for individual samples ranged between 0.11 and 1.99 for transverse deformation, and between 0.15 and 1.87 for longitudinal deformation. The samples were divided into three groups delimited by thickened vertical lines. In the first group (samples 1-3) the deformation in longitudinal direction was nearly zero, probably because of the small pressure changes due to the osmotic treatment (the cells were probably not fully turgid at the beginning of the experiment). The largest, second group (samples 4-13) represents typical cell behavior. In the third group, the strips shrank in both directions. (B and C) Cell scale measurements: cell strain variation in two epidermal strips (B, C) originating from scales from different onions. SEM micrographs show the surface of two epidermal strips in turgid (B1, C1) and plasmolysed (B2, C2) states. Colormaps representing the strain in area (B3, C3) and the pattern of wrinkles (B4, C4), are shown for the same groups of cells, labelled with asterisks in the micrographs (B1, C1). (B) Micrograph of sample 1 shown in the Supplementary data (Fig. S4B ${ }^{2}$ ). (C) Micrograph of sample 4 shown in the Supplementary data (Fig. S4B ${ }^{2}$ ). Scale bars $=200 \mu \mathrm{m}$.
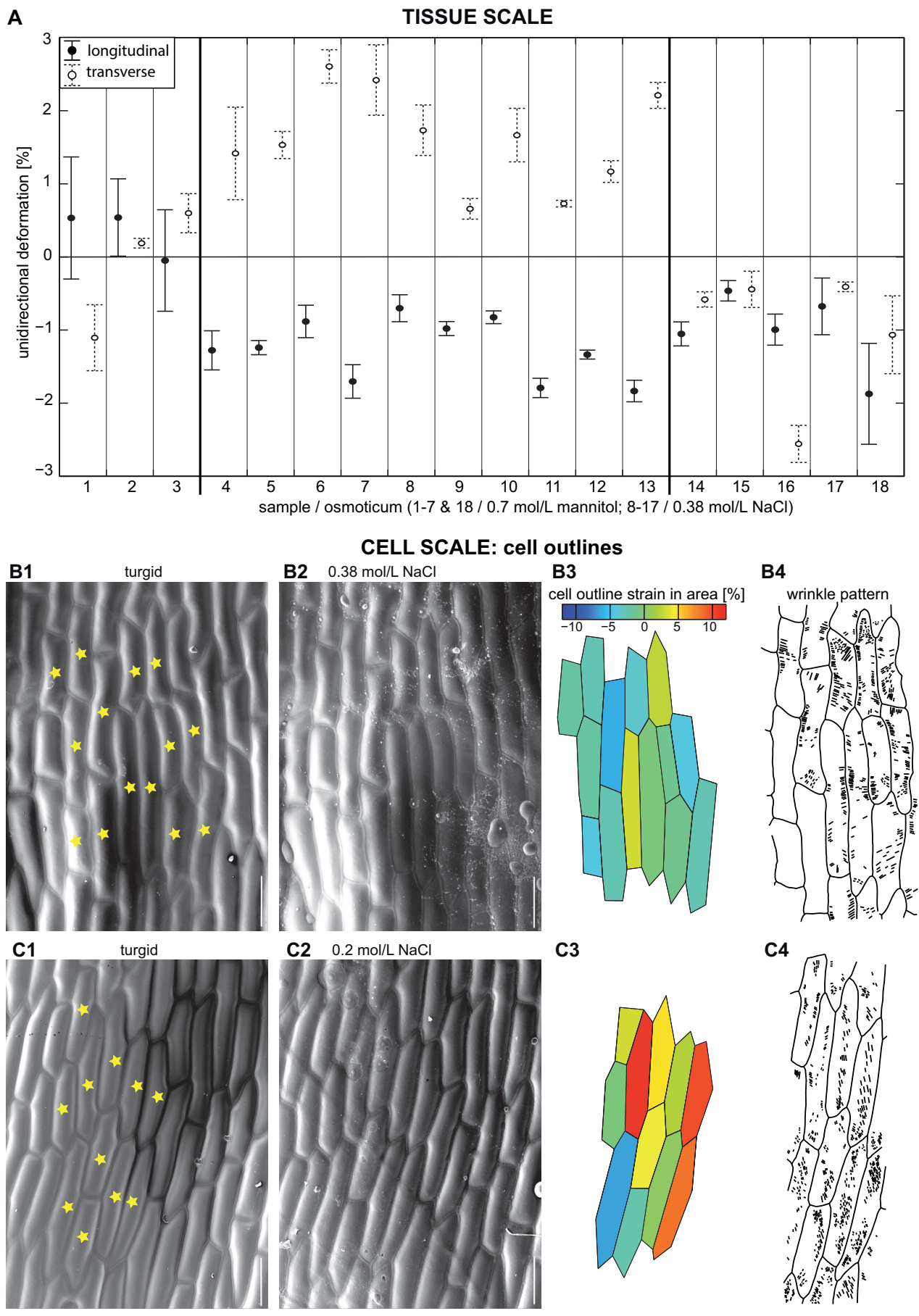

C3
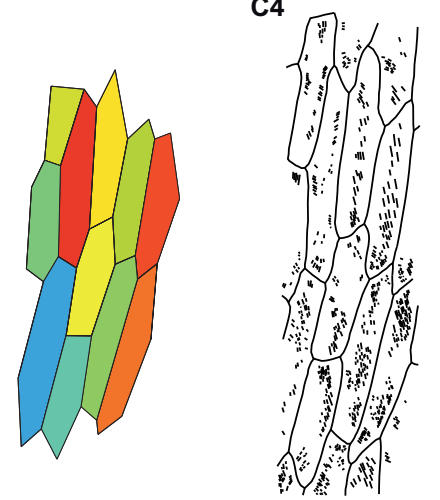
Supplementary data, Fig. $\mathrm{S1B}^{2}$ ), or $0.38 \mathrm{~mol} / \mathrm{L} \mathrm{NaCl}$, causing apparent plasmolysis (Supplementary data, Fig. S1A ${ }^{2}$ ). The higher concentration was used for comparison, because with this concentration we were sure that all the cells were plasmolysed, because the samples were not examined under a microscope before taking the second replica. After taking the scale fragment out of the solution, the surface of the inner epidermis was quickly dried using filter paper, and the second replica was taken immediately. The replicas were used as moulds to obtain epoxy resin casts that were sputter-coated and observed under a scanning electron microscope (SEM; Philips XL30 TMPESEN).

A stereopair of SEM images (two images tilted by $10^{\circ}$ with respect to each other) were obtained for each examined replica, and the epidermis surface was reconstructed using the stereoscopic reconstruction protocol (Routier-Kierzkowska and Kwiatkowska 2008). Local cell wall curvature in turgid and plasmolysed tissue was then assessed by overlaying a group of seven hexagons on a surface of interest (a patch of reconstructed surface of a periclinal cell wall located at the center or near the tip of a cell). The directions and values of the maximal and minimal curvatures were computed for the central hexagon by a least squares fitting of a quadratic surface to vertex coordinates of all the seven hexagons, followed by computation of the fundamental forms of the surface (Dumais and Kwiatkowska 2002). For the same samples, the strain that took place due to osmotic treatment was computed for individual cells. The coordinates of three-way cell wall junctions describing the outline of individual cells [Fig. 1A (A4)] were obtained from the reconstructed surfaces, and projected on the mean plane determined by least squares. For these $2 \mathrm{D}$ coordinates, the outline strain in area was calculated as $\left(A_{\mathrm{p}}-A_{\mathrm{t}}\right) / A_{\mathrm{t}}$ (in percent), where $A_{\mathrm{t}}$ is the surface area of the projected cell outline in turgid tissue, and $A_{p}$ is the surface area of the projected cell outline in plasmolysed tissue. All of the processing programs were written in Matlab (Mathworks, Natick, Massachusetts, USA). The software is available from the corresponding author upon request. Seven samples were analyzed. Strain was assessed for 70 cells (5-14 cells per sample), while local curvature for 134 wall patches (1-4 per cell) was assessed in 100 cells (7-19 cells per sample).

\section{Nomarski microscopy and quantification of wrinkle arrangement}

Isolated epidermal strips, $5 \mathrm{~mm} \times 5 \mathrm{~mm}$, were plasmolysed for $10-15 \mathrm{~min}$ in $0.2 \mathrm{~mol} / \mathrm{L} \mathrm{NaCl}$, covered with a glass coverslip, and examined using a light microscope (Nikon Eclipse 80i) equipped with a Nomarski differential interference contrast system. First, a sequence of overlapping images were taken from a group of adjacent cells and concatenated using NIS-Elements BR 4.10.00 (Nikon) software to obtain the pattern of cell outlines (Supplementary data, Fig. S2A ${ }^{2}$ ). Next, several images of higher magnification were obtained for each cell at subsequent focal planes, such that various portions of the protoplast-facing surface of the outer periclinal wall were in focus and local patterns of wrinkles were visualized [Fig. 1B (B2); Supplementary data, Fig. S2B²). Based on these stacks of images, the wrinkles were mapped for the whole periclinal wall of each cell and overlaid on the cell outline pattern using CorelDRAW X6 (Corel Corp.). The maps were used to assess the orientation and alignment (anisotropy) of wrinkle arrangement using the FibrilTool (Boudaoud et al. 2014) plug-in for Image 1.48v (https://imagej.nih.gov/ij/). Two samples, consisting of 16 or 17 cells, obtained from two different epidermal strips were analyzed.

Nomarski microscopy was also used to examine the pattern of wrinkles for the epidermal strips from which the replicas were taken. Directly after taking the second replica, the strip of the epidermis was isolated and observed under Nomarski microscopy in the same osmoticum as used for the replica. To map the wrinkle pattern in the cells for which the strain was computed, a sequence of overlapping images was taken from the strip and concatenated using NIS-Elements BR 4.10.00 software so that both the cell outlines and wrinkle patterns were imaged. The cells visualized using SEM were identified in the concatenated image. This was done for all of the samples from which the replicas were taken.

\section{Method used to expose the protoplast-facing surface of outer periclinal walls}

First, a scale fragment circa $20 \mathrm{~mm} \times 20 \mathrm{~mm}$ was isolated, and then the epidermis on its inner surface was cut with a razor blade into $10 \mathrm{~mm} \times 10 \mathrm{~mm}$ portions. These portions remained attached to the scale and were dried in a gentle stream of room-temperature air using a hairdryer. The dried epidermal strips were isolated and attached to the surface of a glass slide with the outer periclinal wall facing the slide, using double-sided Scotch tape. Next, the samples were dried again and another piece of tape was attached to the exposed epidermal surface (i.e., to the inner periclinal wall) and was slowly moved away. This broke the anticlinal walls, and the inner periclinal walls were peeled off while the protoplast-facing surface of the walls of interest (i.e., the outer periclinal walls) became exposed [Fig. 1B (B3 and B4)]. The procedure was used to obtain samples to be examined using polarized light microscopy and atomic force microscopy (AFM).

\section{Measurements of microfibril angle using polarized light microscopy}

Samples used in polarized light microscopy were plasmolysed in $0.38 \mathrm{~mol} / \mathrm{L} \mathrm{NaCl}$ for $10 \mathrm{~min}$ and the protoplastfacing surface of outer periclinal walls was exposed using the procedure described above. Microfibril angle was assessed separately for the central portion of each cell, and for the cell tips using a polarized light microscope (Nikon Eclipse 50i Pol). The measurements 
were performed as described earlier (Leney 1981; Borowska-Wykręt et al. 2017). Thirty cells from 12 epidermal strips (3-4 cells per strip) originating from 12 different onions were analyzed.

\section{Atomic force microscopy and quantification of cellulose microfibril arrangement on protoplast-facing wall surface}

Samples of outer periclinal walls used for AFM analysis were obtained using the procedure to expose the protoplast-facing surface described above, followed by rinsing for $15 \mathrm{~min}$ in ultrasonic cleaner (SONIC2; Polsonic Poland) in a solution of $5 \% \mathrm{NaOH}$ to expose the cellulose microfibrils and remove the protoplast remnants. AFM measurements were performed using a NanoWizard3 BioScience instrument (JPK Instruments, Berlin, Germany) operating in contact mode equipped with triangular SiNi cantilevers (Budget Sensors, spring constant $0.06 \mathrm{~N} \cdot \mathrm{m}^{-1}$ and $0.27 \mathrm{~N} \cdot \mathrm{m}^{-1}$ ). All of the scans were conducted under air and under laboratory conditions (room temperature, humidity of $45 \%$ ). Vertical deflection images of the wall surface, $3 \mu \mathrm{m} \times 3 \mu \mathrm{m}$ [Supplementary data, Fig. S3 (A1 and B1) ${ }^{2}$, were obtained using the JPK Data Processing software (JPK Instruments). Each image was divided into 36 equal square-shaped fragments, and line segments approximating orientation of apparent cellulose microfibrils (1-19 per fragment) were overlaid on each fragment using CorelDRAW X6 [Supplementary data, Fig. S3 (A2 and B2)]. The orientation of these line segments with respect to the long axis of the cell was measured using ImageJ, and mean microfibril orientation in each of the image fragments was computed for directional data (Zar 1999) using the CircStat toolbox (Berens 2009) of Matlab. The measurements were performed on five images obtained from central wall portions of cells originating from different onion scales.

\section{Light microscopy and measurements of cell wall thickness}

Hand-cut transverse sections of onion epidermis (several dozen micrometres thick), obtained using a razorblade, were put on glass slides, immersed in water, covered with glass coverslips, and examined under a light microscope (Nikon ECLIPSE 80i) equipped with 40x /0.75 objective and digital camera (DS-Fi2). The thickness of the outer periclinal walls was measured in high resolution images of the sections using CorelDRAW Graphics Suite X4 (Corel Corp.). The walls of seven cells from three sections obtained from three onions were used for the measurements. The thickness of each wall was measured in three different places.

\section{Modelling}

A finite element method (FEM) model of the onion epidermis (a cell monolayer) was constructed from a template of the onion epidermal surface segmented with the image processing software MorphoGraphX (de Reuille et al. 2015). The surface layer of cells was flattened and simplified by keeping only the boundaries of cells with an average spacing of vertices of approximately $7 \mu \mathrm{m}$. The cells were then extruded with five segments (each $5 \mu \mathrm{m}$ long) in the direction normal to the cell surface to create a layer of $3 \mathrm{D}$ cells with a uniform depth of the anticlinal walls of $25 \mu \mathrm{m}$. The walls were then triangulated (Shewchuk 1996). The cells were separated (i.e., vertices on shared walls duplicated), and all but the central three segments smoothed to give the cells a rounded shape on the top and bottom. This 3D cellular triangle mesh was then extruded $2 \mu \mathrm{m}$ to create volumetric wedge elements for the cell walls, and outer faces and vertices of shared walls merged. The mean thickness of the outer periclinal walls of onion epidermis, measured using light microscopy, is $5.6 \mu \mathrm{m}$ (standard variation = $0.4 \mu \mathrm{m}$ ) but the inner walls are much thinner (see also Suslov et al. 2009). Thus, we chose the intermediate thickness of $2 \mu \mathrm{m}$ for all of the walls. The shape of such template closely mimicked the real tissue (compare Figs. 3A and 6A).

Comparisons between simulations and experimental results were performed with the wedge elements assigned uniform material properties using a Saint Venant transverse isotropic material model (linear, large deformation), fully compressible, with Young's modulus of $100 \mathrm{MPa}$ in the longitudinal direction, and $500 \mathrm{MPa}$ in the transverse direction and the direction normal to the wall. Empirical data on the modulus are only available for the outer periclinal walls of abaxial epidermis (3.7 GPa in the longitudinal direction, and 4.9 GPa in the transverse direction; Zamil et al. 2013) rather than adaxial, or for the whole adaxial epidermis instead of the cell wall (59 MPa; Vanstreels et al. 2005). We thus used the intermediate values. A uniform pressure of 0.7 MPa was applied to the interior faces of the cells. FEM simulations were performed using the MorphoMechanX (www. MorphoMechanX.org) simulation software, which is currently under development and is an extension of the software platform used in Bassel et al. 2014, Mosca et al. 2017, and Sapala et al. 2018. The curvature for a given location on the cell wall was estimated based on all vertices within $20 \mu \mathrm{m}$ (Goldfeather and Interrante 2004), as in MorphoGraphX (de Reuille et al. 2015).

\section{Software used for figures and statistical analysis}

Statistical analysis (descriptive statistics, sample median or mean comparison using Kruskal-Wallis and Student $t$ tests, polar plots), image processing, and artwork preparation were performed using Matlab, Adobe Design Premium CS4 (Adobe Systems Inc.) and CorelDRAW X6.

\section{Results}

Osmotic treatment led to small deformations of the onion epidermis surface

We assessed surface deformation of the osmotically treated epidermis at both the tissue and cell scales [Fig. 1A (A1)]. To maximize the deformation, prior to the 
Fig. 3. Deformation of outer periclinal cell walls due to osmotic treatment. (A) Optical cross-section obtained from confocal stacks showing the epidermal cell shapes in the turgid and plasmolysed states. White lines represent the contours of the outer periclinal walls. Note that the walls remain curved after osmotic treatment. (B) Histogram of the strain in area assessed for the periclinal wall surface of all the examined cells $(n=110)$, based on confocal microscopy images. (C-F) Changes of curvature of outer periclinal cell walls assessed using the in vivo replicas. The curvature was computed for wall patches located near the tips or in central parts of the cells. Directions of maximal and minimal curvatures, represented by cross arms, were overlaid on the SEM micrographs showing the same epidermis surface in turgid and plasmolysed states. Curvature was computed for each central polygon based on positions of vertices of all the polygons (thin white lines). The cross arms are black if in this direction the wall surface is convex, and white (D1 and F1) if it is concave. The longer the arm, the higher the curvature. The asterisk in D1 labels the rectangular cell tip that is curved both in longitudinal and in transverse direction. Scale bars $=100 \mu \mathrm{m}$.

\section{CELL SCALE: outer periclinal walls}
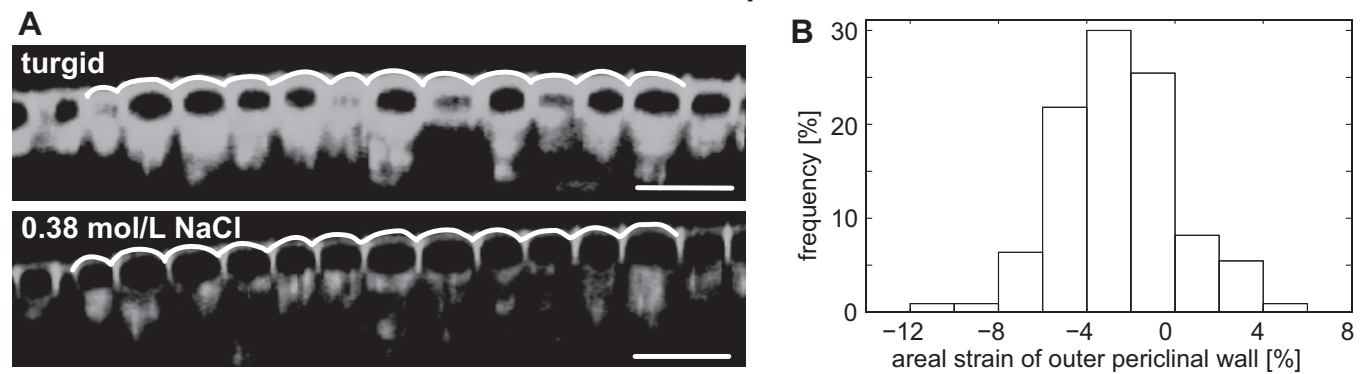

local wall curvature
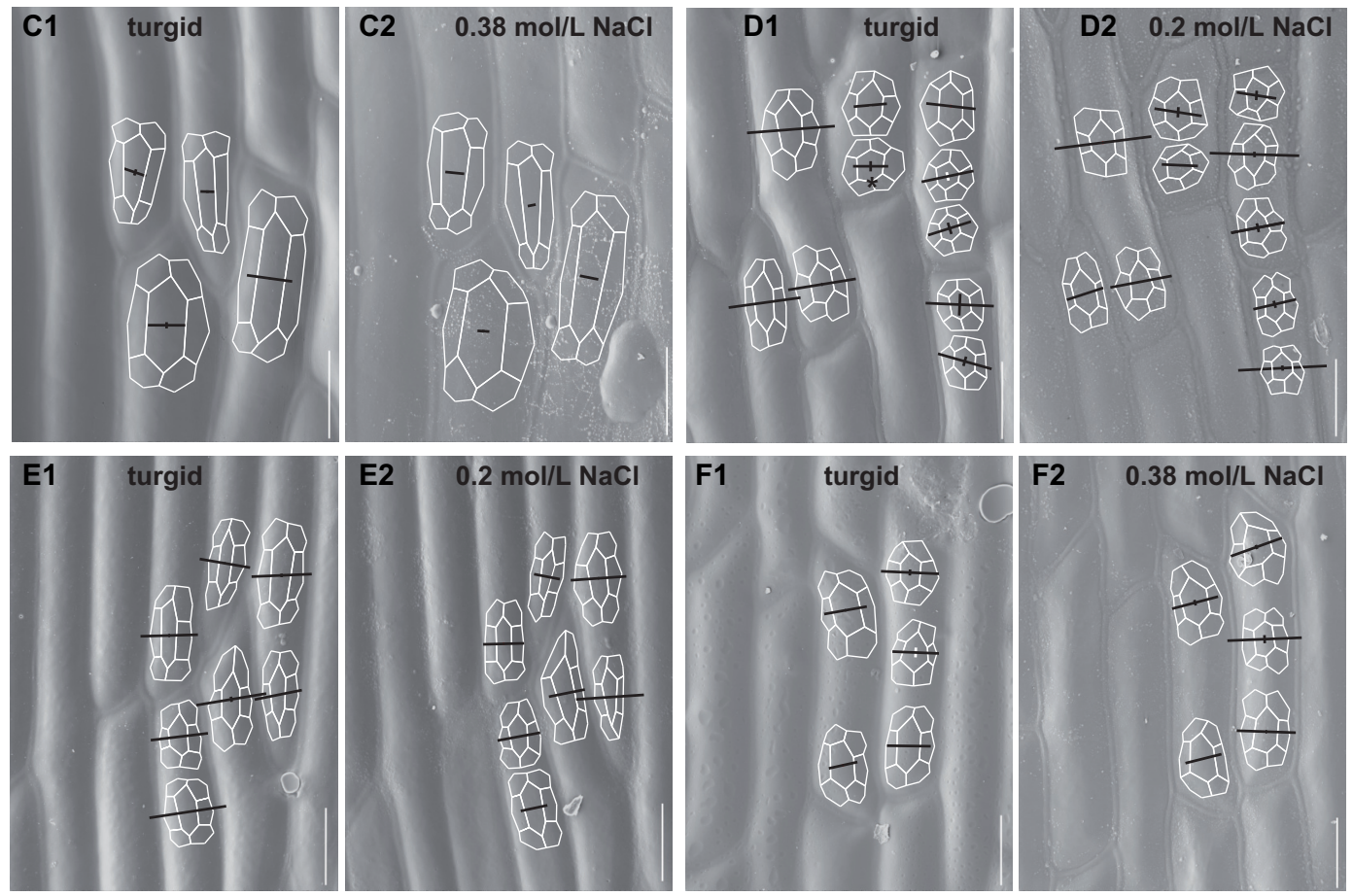

treatment with the hypertonic solution, the samples to be examined under light or confocal microscopy were kept in water (hypotonic solution). Based on direct microscopic observations of the epidermal strips, we measured unidirectional deformation at the tissue scale (Fig. 1A1) using two types of osmoticum, causing apparent plasmolysis (Fig. 2A). The osmotic treatment induced a drop of turgor pressure by no more than $1.0 \mathrm{MPa}$ (assessed by Van't Hoff equation using $0.2 \mathrm{~mol} / \mathrm{L} \mathrm{NaCl}$, i.e., osmoticum causing incipient plasmolysis). The mean unidirectional deformation of all the strips was very small, ranging between $2.5 \%$ shrinking and $2.5 \%$ exten-

sion. For the individual strips, strain in the longitudinal direction, i.e., parallel to cell axes (dots in Fig. 2A), was usually different from the strain in the transverse direction (circles in Fig. 2A). Independent of the applied osmoticum, the strips tended to shrink in the longitudinal direction, and to extend in the transverse direction (10 out of 18 samples behaved this way, see Fig. 2A), with the amount of transverse extension being generally higher than the longitudinal shrinking. Note that the extension was not expected as a result of cell deflation. From such anisotropy of deformation we expected that the areal strain of the strips would be close to zero. Indeed, the 
areal strain of polygons [Fig. 1A (A1)] that covered most of the strip surface was very small (the mean for samples 4-13 from Fig. $2 \mathrm{~A}$ was $-0.05 \%$ with a standard deviation of $1.57 \%$ ).

Next, we measured the strain at the cellular scale. Using the in vivo replica method, we assessed the strain in area of cell outlines, approximated by polygons defined by three-way cell wall junctions [Figs. 1A (A4), 2B, and 2C). The areal strains for the outlines of individual cells differed between neighboring cells [Fig. 2 (B3 and C3)]. The strain ranged between circa $12 \%$ shrinking [blue cells in Fig. 2 (B3 and C3)] and 12\% expansion (red cells), but for the majority of cells the value was close to zero (Supplementary data, Fig. $S 4 \mathrm{~A}^{2}$ ) similar to the areal strain at the tissue scale. Median areal strains for individual samples were between 5\% shrinking and 3\% expansion (samples 3 and 4 in the Supplementary data, Fig. S4B, respectively ${ }^{2}$.

The strain of cell outlines corresponds to the whole strip strain, because in both cases the changes in distance between three-way cell junctions are considered while the changes in the surface area of periclinal cell walls are not. Thus, neither the cell outline nor the whole strip strain represents the strain of the curved periclinal cell walls (compare A3 and A4 in Fig. 1A), which are expected to shrink when turgor pressure drops due to osmotic treatment. Thus next we assessed the strain in area of the outer periclinal wall surface using in vivo confocal microscopy (Figs. 3A and 3B). As expected, the periclinal walls in most of the cells were shrinking upon pressure loss.

The difference between the areal strains of cell outlines and periclinal walls was confirmed by further examination of SEM micrographs that showed that the osmotic treatment was often accompanied by changes in wall curvature [compare e.g., $\mathrm{C} 1$ and $\mathrm{C} 2$ in Fig. 3). Thus, next we assessed the curvature for selected patches of wall surface in turgid and osmotically treated cells [Fig. 3 $(\mathrm{C}-\mathrm{F})]$. In all of the cases, the wall surface was convex in the direction transverse to the cell axis (the direction of maximal curvature), whereas it was usually almost flat in the longitudinal direction (the direction of minimal curvature). The only exception of the second trait were patches located near the rectangular tips of cells [marked with asterisk in Fig. 3 (D1)] located near cell tips. The mean maximal curvature computed for all the turgid cells (mean $=0.0088 \mu \mathrm{m}^{-1}$; $\mathrm{SD}=0.0044$ ) was not significantly different ( $t$ test, $p=0.39$ ) from the curvature of osmotically treated cells $\left(\right.$ mean $=0.0093 \mu \mathrm{m}^{-1}$; $\mathrm{SD}=$ 0.0041). However, comparison of individual wall patches showed that the periclinal walls of some cells apparently flattened due to the osmotic treatment (the maximal curvature decreased in $39 \%$ of patches, e.g., Fig. 3C), while the wall surface curvature of other cells was almost unchanged (in 19\% of patches the curvature changed by less than $0.001 \mu \mathrm{m}^{-1}$; e.g., top right cell in Fig. 3E). In some cells the periclinal wall became even more curved (the curvature increased in $42 \%$ of patches, e.g., Fig. $3 F$ ).

In summary, the measurements showed that the strains and the curvature changes due to the drop in turgor pressure caused by osmotic treatment were small, whereas the behavior of individual cells and of individual tissue strips varied. In general, osmotic treatment led to surface shrinking of periclinal cell walls and equally represented decrease and increase of wall curvature. This wall behavior was accompanied by anisotropic deformation of epidermal strips, which usually extended in a transverse direction and shrunk longitudinally. However, one has to keep in mind that in the case of such small deformations, the measurement results can be biased by errors originating from imprecisions of the wall junction digitization or surface reconstruction.

\section{Stress removal leads to wrinkling of protoplast-facing layer of outer periclinal walls}

In the majority of examined cells, the osmotic treatment led not only to changes in cell outlines and surface curvature but also to the wrinkling of the protoplastfacing surface of outer periclinal walls, i.e., the youngest wall layers [Figs. 1B (B2), and 2 (B4 and C4); Supplementary data, Fig. S2 ${ }^{2}$. The wrinkles disappeared during deplasmolysis, and a similar wrinkle pattern reappeared when the cells were plasmolysed again (see the Supplementary data, Fig. S5 ${ }^{2}$ ). Previous investigations showed that such wrinkling is a manifestation of the wall layer buckling after the removal of tensile in-plane stress from the wall (Hejnowicz and Borowska-Wykręt 2005; Lipowczan et al. 2018). Because the orientation of wrinkles is related to the anisotropy of the wall strain, the wrinkling pattern may be used to assess the anisotropy of osmotically induced strain at the subcellular scale. In particular, we expected that the wrinkles would be perpendicular to the direction of maximal shrinkage, and that the strong strain anisotropy would lead to lower variation in wrinkle orientation.

We analyzed variation in wrinkle orientation within and among the cells using detailed maps showing the wrinkle pattern on the whole protoplast-facing surface of outer periclinal walls (Supplementary data, Fig. S2 ${ }^{2}$; Fig. 4A). On this basis we distinguished three portions within each cell. The shape of the central portion of the periclinal wall not in contact with margins or tips of the cell resembled a cylinder (Fig. 4A, exemplary regions marked by red rectangles). There, the wrinkle orientation was nearly longitudinal (Fig. 4B) and the wrinkles were mostly aligned [Fig. 4C; Supplementary data, Fig. S2 $\left(\mathrm{B}^{2}\right)$ ]. Along the margins of the periclinal walls (Fig. 4A, blue rectangles), the wrinkles were usually nearly transverse, i.e., perpendicular to the adjacent anticlinal walls (Fig. 4B). At the tip of the cells the wrinkle pattern was related to the shape of the tip. Wrinkles from the central portion of the cells extended into a fountain-like pattern toward the tips [Fig. 4A, green rectangular outlines; 
Fig. 4. Variation in the pattern of wrinkles formed on the youngest layer of outer periclinal cell walls. (A) The wrinkle pattern in a group of adjacent cells differing in tip shape. Examples of the central portions of a periclinal wall surface, the shape of which approximates a cylinder, are labeled with red rectangles; the margins adjacent to anticlinal walls are indicated with blue rectangles; cell tips with a fountain-like wrinkle arrangement are indicated with green rectangular outlines; and hoopshaped wrinkles are indicated with green rectangles. A black rectangular outline indicates an example of a region where the wrinkle pattern matches in adjacent cells. An asterisk indicates that this is the same cell as presented in the Supplementary data (Fig. S2A 2). (B) Orientation of wrinkles with respect to the cell axis in the three types of cell-wall portions. Each circle represents the average wrinkle orientation in a central portion of an individual cell or in one of the cell tips or margins. For each set of measurements the mean resultant vector (thick black line segment) is plotted such that the longer the vector, the lower the circular spread of the data. Zero corresponds to an alignment parallel to the cell axis (longitudinal direction). (C) Alignment of wrinkles in the same regions as shown in polar plots (B). Anisotropy $=1$ for perfectly aligned wrinkles; $0=$ an isotropic arrangement. The thick line within each box represents the median; the box delimits the first and third quantiles; whiskers extend from each end of the box to the adjacent values in the data as long as the most extreme values are within 1.5-times the interquartile range from the box limits.
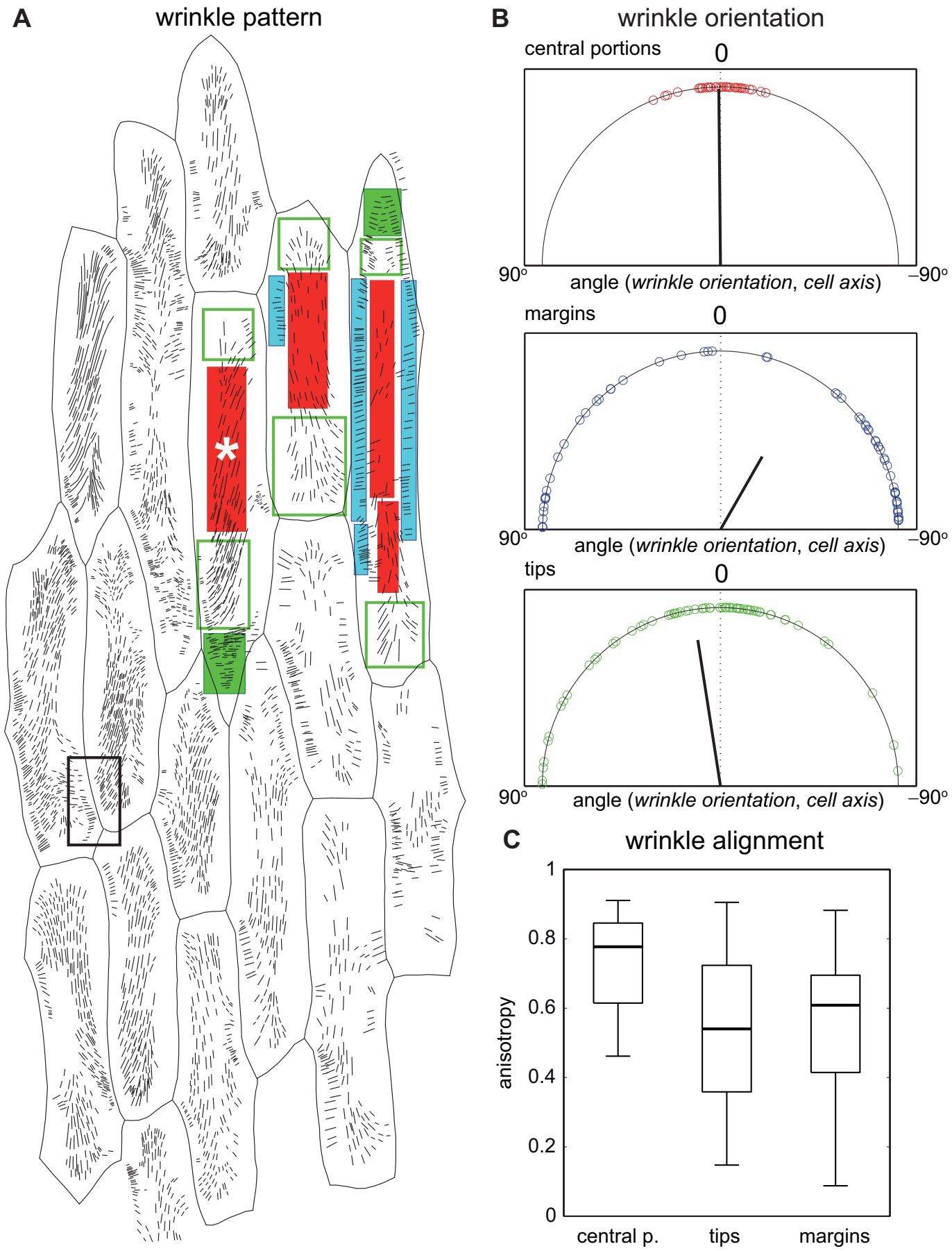

- Published by NRC Research Press 
Fig. 5. Orientation of cellulose microfibrils in the outer periclinal cell walls of adaxial onion epidermis. (A) Microfibril angle measured under polarized light microscopy for the central portions $(n=30)$ and tips $(n=60)$ of the same cells. Each circle represents one cell or one cell tip. Mean resultant vectors are plotted in the same way as in Fig. $4 \mathrm{~B}$. An angle of $0^{\circ}$ for microfibrils corresponds to an alignment parallel to the cell axis (longitudinal direction). Note that two microfibril orientations dominate: transverse, and to a lesser extent, longitudinal. (B) Histogram showing the absolute values for the difference between the microfibril angle in the center and the tips of individual cells $(n=60)$. In the majority of cells, the microfibril angle is similar at the central portion and at the tips. (C) Microfibril angle of the inner wall layer in the central portions of individual cells. Each circle represents the mean orientation of individual microfibrils recognized in one of 36 fragments of the same atomic force microscopy image of the cell wall (see also the Supplementary data, Fig. S32 ${ }^{2}$. MFA, microfibril angle.
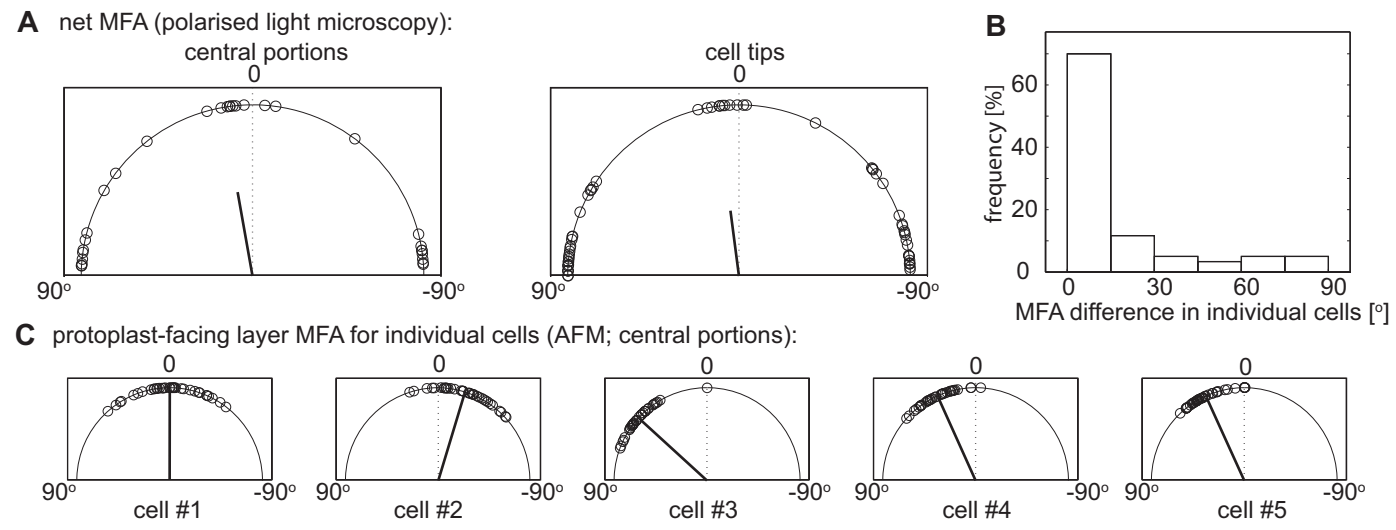

Supplementary data, Fig. S2 $\left.\left(\mathrm{B}^{2}\right)\right]$. This fountain-like pattern was characteristic for tips of a rectangular or only slightly elongated shape. At elongated and pointed (acute) tips, a group of hoop-like wrinkles was formed [Fig. 4A, green rectangles; Supplementary data, Fig. S2 $\left.\left(\mathrm{B}^{2}\right)\right]$. Both the fountain-like and hoop-like patterns extended into wrinkles that were orthogonal to the adjacent anticlinal walls. At the supracellular scale, the wrinkle pattern was generally continuous (black rectangular outline in Fig. 4A), which was related to the prevalence of orthogonal orientation of marginal wrinkles with respect to anticlinal walls.

In summary, the formation of wrinkles on the wall surface facing the protoplast in all the examined samples confirmed the cell wall shrinkage due to osmotic treatment. The pattern of wrinkling was regular, and depended on the position of the wall patch along the cell axis (cell center vs. tip) and the distance from the anticlinal walls. In previous experiments the pattern of wrinkles was uniform in all the cells, and wrinkles were normal to the direction of the maximal wall shrinking (Hejnowicz and Borowska-Wykręt 2005; Lipowczan et al. 2018). In these previously studied tissues, unlike in onion epidermis, the deformation was large, strongly anisotropic with maximal shrinking along the cell axis, and similar in all the cells. From this perspective, the formation of wrinkles in the onion epidermis is a more interesting phenomenon because the wrinkle pattern is more complex and the cell wall deformations are more variable. However, in the onion epidermis where the strain is very low, comparisons between the wall deformation and wrinkle pattern are not possible, because the assessment of strain anisotropy would be strongly biased by segmen- tation errors, while subcellular variation in strain cannot be assessed due to the lack of surface landmarks. To address this problem, we developed a mechanical simulation of the osmotic experiment on a geometrically realistic template to provide more insight into the mechanical behavior of the epidermal tissue monolayer.

\section{Orientation of cellulose microfibrils in outer periclinal walls differs among and within cells}

The anisotropy of cell wall strain is related to the direction of the wall reinforcement by cellulose microfibrils (Kerstens et al. 2001). Therefore we next examined the orientation of cellulose microfibrils across the whole wall thickness (net orientation) using polarized light microscopy, and in the youngest wall layer facing the protoplast using AFM (Fig. 5; Supplementary data, Fig. S32). Results from both measurements show some variation among individual cells. The net microfibril orientation was either nearly transverse (microfibril angle close to $90^{\circ}$ or $-90^{\circ}$ ) or, less often, nearly longitudinal (microfibril angle close to $0^{\circ}$ ). Oblique orientation was only infrequently represented (Fig. 5A). The microfibril angle in the central cell portion was similar to that of the cell tips, although cells with a large difference in microfibril angle between the two cell portions were also represented (Fig. 5B). These results are in agreement with the net cellulose orientation assessed using polarized confocal microscopy for the epidermis of outer scales of nearly mature onions (Suslov et al. 2009).

Orientation of individual cellulose microfibrils on the wall surface facing the protoplast was not uniform and resembled a polylamellate arrangement [Supplementary data, Fig. S3 (A1 and $\mathrm{B}^{2}$ )] reported for the outer (abaxial) 
Fig. 6. Results for the mechanical model of the osmotic treatment experiments. (A) Side-view of the mechanical model of the onion epidermal strip. Tissue geometry was extracted from confocal microscopy images of an adaxial onion scale epidermis using MorphoGraphX software. The 3D cells were created by extracting the surface cells, extruding the cell outlines, and smoothing to give realistic shapes before pressurization (lower image). The upper image shows the cells after pressurization. Note how the curvature on the top of the cells changes, and that the tissue shrinks in width upon pressurization. (B and C) Color maps showing the areal strain of the cell outlines $(\mathrm{B})$ and of the outer periclinal cell walls $(\mathrm{C})$ computed for the change from the pressurized to non-pressurized state. The lines overlaid in (B) show the principal directions of strain of the cell outline. The line lengths represent the amount of deformation in this direction; lines are white for extension, red for shrinking. (D and E) Color maps showing the local maximal curvature of periclinal cell walls for the tissue in a pressurized (D) and a non-pressurized (E) state. The lines represent the principal directions of curvature (line length indicates the curvature in this direction) in the examples of patches of the wall. Asterisks mark typical cell tips of rectangular shape. Note that upon pressurization (D) the walls of the cells near the margins become more curved than the walls of the inner cells. A somewhat similar effect in the non-pressurized tissue occurs due to smoothing while the template was being created. Therefore, the cells near the margin were excluded from the quantification of shape change in the model (see also the Supplementary data, Fig. S6 ${ }^{2}$ ).

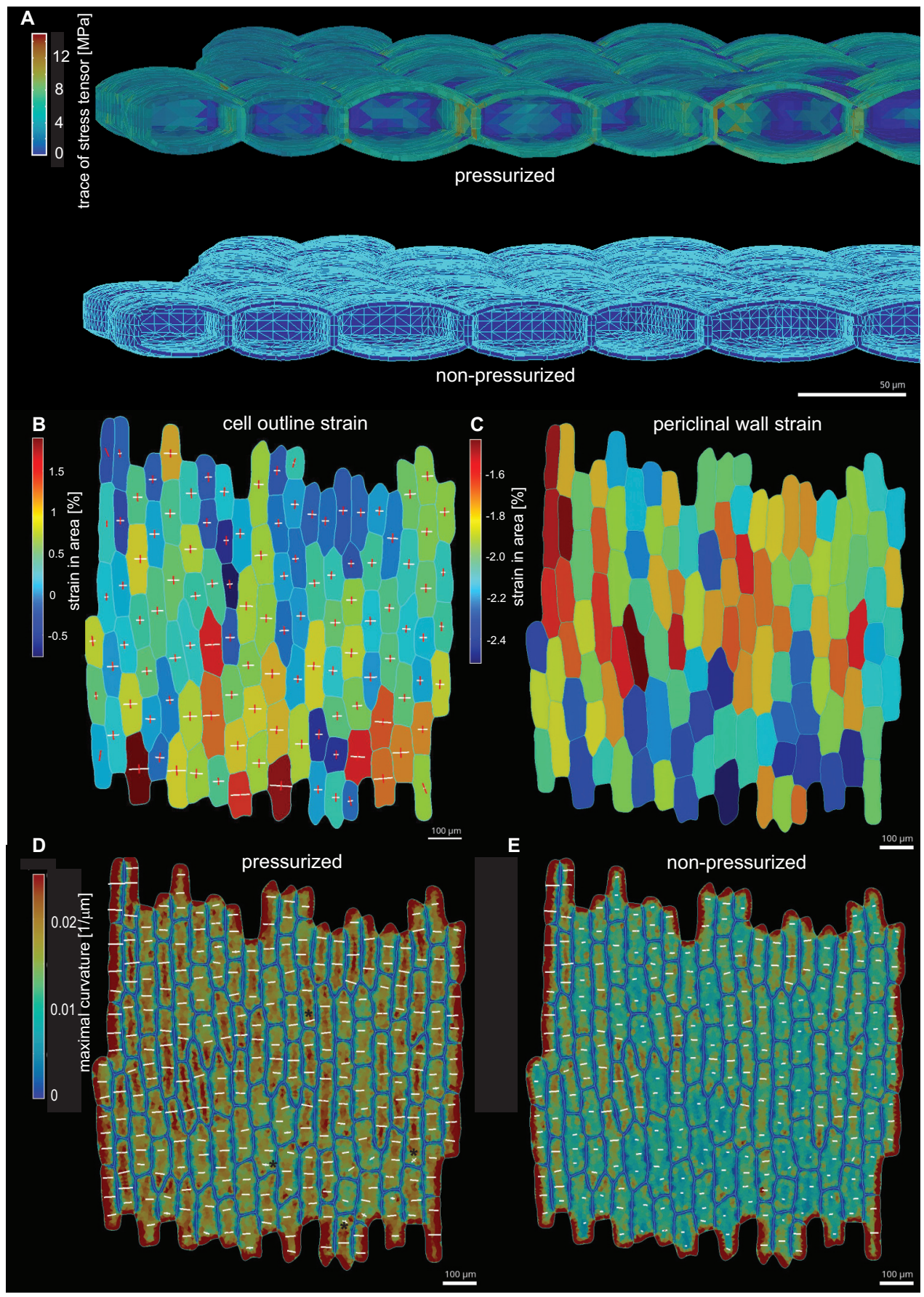


onion epidermis (Zhang et al. 2014). Nevertheless, oblique microfibrils prevailed [Supplementary data, Fig. S3 (A2 and $\left.\mathrm{B}^{2}\right)$ ], and the average microfibril orientation in patches from individual cell walls ranged from oblique (circa $45^{\circ}$ ) to longitudinal (Fig. 5C).

In summary, the wall reinforcement by cellulose microfibrils differed between cells. Two net orientations dominated; transverse and less often longitudinal, while microfibril orientations on the wall surface facing the protoplast were to various extent oblique.

\section{Mechanical model simulates osmotic treatment experiments}

To gain more insight into the mechanics of the epidermal tissue monolayer, we developed a mechanical model using cell shapes extracted from the same samples as used in the osmotic treatment experiments (see Materials and methods; compare Figs. 3A and 6A). During the simulations, non-pressurized cells of the tissue template were pressurized to compute the deformation of cell walls and the tissue (note that this process is opposite to the empirically investigated deformation accompanying the loss of turgor pressure). We found that even with isotropic material, the tissue would always shrink in width when pressurized, if the stiffness and pressure parameters were such that unidirectional deformation was limited to $2 \%$, which is comparable to our experimental results. This corresponds to transverse expansion of the onion epidermal strips during the reverse process, i.e., the turgor pressure loss (see Fig. 2A). This counterintuitive shrinking upon inflation, or "air-mattress effect", is caused by the geometry of the cells. As the cells are pressurized, the periclinal walls bulge out, pulling the anticlinal walls closer together. Because the density of anticlinal walls is higher along the transverse direction (perpendicular to the long axis of the cells), the effect in the transverse direction is stronger than in longitudinal direction. In the long and thin cells of the onion epidermis the effect is compounded, because in-plane wall stress is higher in the hoop (transverse) direction like in an isolated cylindrical cell (Hejnowicz 2011). Note that the stresses on the anticlinal walls are spread more evenly than seen in puzzle-shaped epidermal cells, where the stresses on anticlinal walls are concentrated in the indentations (Sapala et al. 2018).

With isotropic material of sufficient stiffness (Young's modulus equal to $500 \mathrm{MPa}$ ), cell wall thickness of $2 \mu \mathrm{m}$, and a Poisson's ratio of 0.3 , the tissue shrank by $2 \%$ in the transverse direction, but only very slightly (less than $0.1 \%)$ in the longitudinal direction when pressurized. If the Poisson's ratio was reduced to 0 , there was a very slight (again less than $0.1 \%$ ) increase in tissue length in the longitudinal direction, and no significant change in the transverse direction. However, the effect was much less than observed experimentally, where the extent of longitudinal shrinking of the onion epidermal strips during the turgid pressure loss was close to the extent of the transverse extension (see Fig. 2A). We therefore assumed that the wall was likely, on average, anisotropic, with the transverse direction being stiffer than the longitudinal, in agreement with the prevalent net orientation of cellulose microfibrils (see Fig. 5A). If the transverse direction was made five times stiffer than the longitudinal direction, the simulations produced strains that were approximately corresponding to those observed in the experiments. To validate the model we compared transverse and longitudinal unidirectional deformations of the real tissue with analogous principal strains of cell outlines in the model (Fig. 6B; note that to simplify the comparison, the strains in Fig. 6 are shown for the change from pressurized to non-pressurized state). Areal strains of cell outlines from the model are shown in Fig. 6B, areal strains of curved periclinal walls in Figs. $6 \mathrm{C}$ and in the Supplementary data (Fig $\mathrm{S6A}^{2}$ ), and cell volume strains in Figs. S6B and S6C ${ }^{2}$. The strains in the simulations were generally less variable than in the experiment, as they were not affected by measurement errors, although there was still variability due to cell shape.

Because the shrinkage of the tissue in the transverse direction is driven by the bulging of the periclinal wall, we compared the changes in curvature of periclinal walls in the simulations (Figs. 6D and 6E) with the experiments (Figs. 3A and 3C-3F). In both the model and the experiments, the wall curvature in the transverse direction was maximal while walls were usually nearly flat in the longitudinal direction. Only walls at rectangular cell tips were also curved in the longitudinal direction (asterisks in Fig. 3D1 and Fig. 6D). The curvatures of pressurized and non-pressurized cell walls were close to experimental values and varied within individual cells as in the experiment. The maximal curvature of individual cells in the model changed upon pressurization similar to some real cells. Although the changes in curvature upon pressurization were approximately similar when using 3D wedge elements (elements with bending stiffness), simulations with 2D membrane elements (triangles) with the same material parameters caused the cells to bulge out excessively. This also resulted in unrealistically large changes in width. Although it has been suggested that membrane elements (without bending stiffness) are suitable for the simulation of plant cells (Bozorg et al. 2014), it appears that in onion epidermis, with its thick outer cell wall, bending stiffness plays a significant role and cannot be neglected.

The simulations provided important data on the periclinal cell wall behavior, which could not be obtained from experiments, i.e., the local strain in wall area and principal directions of strain, that were computed for each wedge element (Fig. 7). Both parameters depended on the shape of the cell outline and varied within individual cells. For example, the wider and less elongated cells bulged more upon pressurization in places where 
Fig. 7. Local variation of strain upon pressurization. (A) and (B) are different fragments of the epidermal strip shown in Fig. 6. Color maps show the areal strain of the top surface of wedge elements comprising the outer periclinal cell walls. Crosses represent the principal directions of strain, with line length depending on deformation in this direction (white for extension, red for shrinking). Red rectangles outline the portions of relatively wide and short cells where the periclinal wall bulges; white rectangular outlines indicate the portions where the direction of maximal strain is nearly perpendicular to the expected orientation of wrinkles; black rectangular outlines indicate the portions where the two directions would not match. Asterisks mark acute (red) or rectangular (white) cell tips. Numbers refer to long (1) or short (2) segments of anticlinal walls.

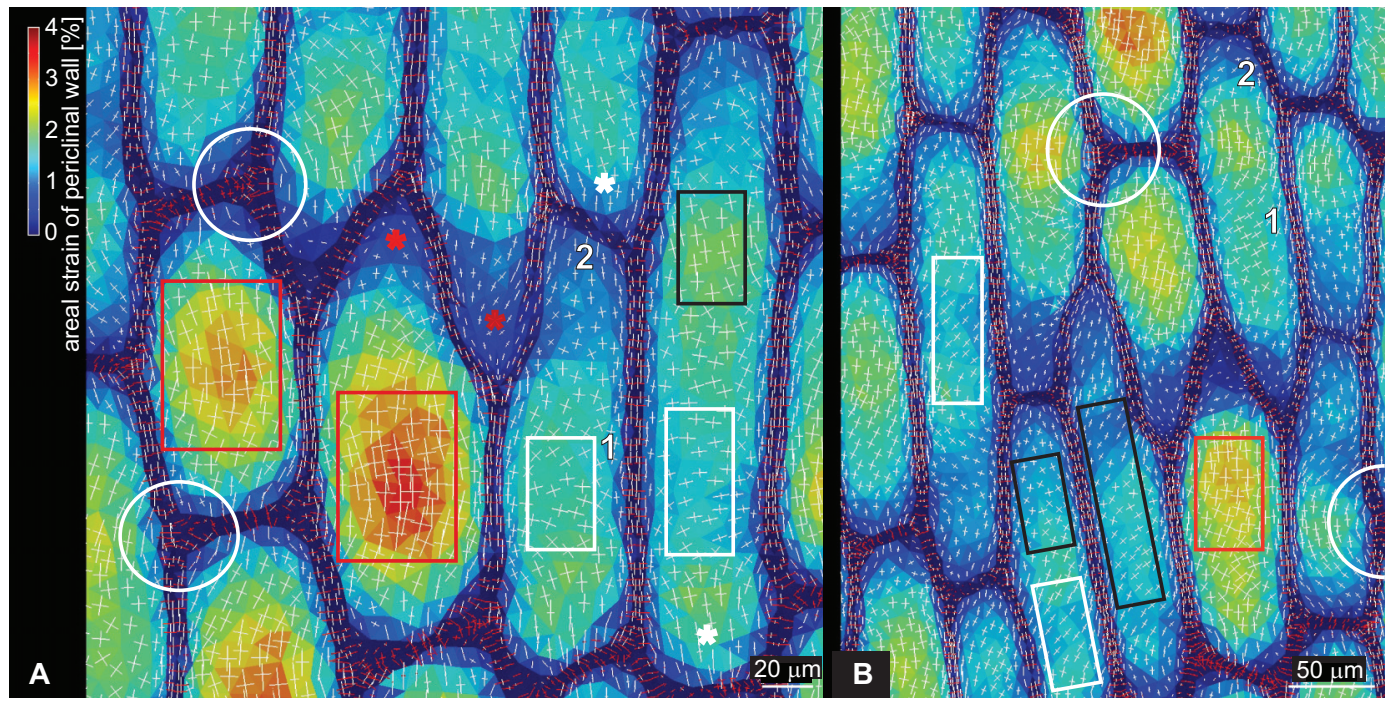

they were relatively wide (Figs. 7A and 7B, red rectangular outlines) (Sapala et al. 2018). In these areas the strain anisotropy tended to be lower, while the areal strains were higher. The lower areal strains were in turn typical for elongated and acute cell tips (Fig. 7A, red asterisks). The principal strain directions near anticlinal walls depended on the anticlinal wall length and the distance from the wall junctions: the maximal strain direction tended to align with the long anticlinal walls (wall 1 in Figs. 7A and 7B), but became oblique or normal to short anticlinal walls (wall 2 in Figs. 7A and 7B) or in the vicinity of the cell wall junctions (white circles in Figs. 7A and $7 \mathrm{~B})$.

We may assume that the cell wall deformation due to the pressure loss would be the opposite to that shown in Fig. 7, with extension in the principal direction being replaced by the same amount of shrinking, and vice versa. With this assumption, we observed that in many places the pattern of wrinkles formed on the protoplastfacing wall surface upon the loss of turgor pressure, seemed to be related to the pattern of principal strain directions. In central parts of elongated cells far from wall junctions, the direction of maximal strain was oblique to nearly transverse (white rectangular outlines in Figs. 7A and 7B) while wrinkles would likely be almost longitudinal, i.e., approximately perpendicular to the direction of maximal shrinking (see Fig. 4A, red rectangles). The longitudinal direction of maximal deformation at the rectangular or slightly elongated tips (Fig. 7A, white asterisks) and at the elongated acute tips (red asterisks) was in agreement with the observed fountainlike and transverse (hoop-like) wrinkles (see Fig. 4A, green rectangular outlines and rectangles, respectively). Also the orientation of wrinkles near the long anticlinal walls was perpendicular to the predicted direction of maximal shrinking [wall 1 in Figs. 7A and 7B; (see also Fig. 4A, blue rectangles)]. However, in some places the wrinkle orientation was not perpendicular to the maximal strain direction. These were mainly the central parts of some cells including portions of wider and less elongated cells that bulged more upon pressurization (black and red rectangular outlines in Figs. 7A and 7B).

\section{Discussion}

Using in vivo imaging we showed that the osmotic treatment of strips of onion-scale epidermis results in small strains. Upon the loss of turgor pressure due to the transfer from hypotonic to hypertonic solution, the onion epidermis undergoes a strain that is lower than the strain of protodermis of tomato shoot apex transferred from isotonic to hypertonic solution (Kierzkowski et al. 2012) or the strain of single cells of tobacco Bright Yellow-2 line (Weber et al. 2015). Because the cells of onion epidermis are no longer growing, their walls are stiffer (Zimmermann 1978). Because the measurements of low strains are more susceptible to errors in segmentation and 3D reconstruction, we complemented empirical data with a mechanical model of tissue deformation in response to cell pressurization, using simplified but realistic shapes of epidermal cells extracted from our samples. Outer periclinal cell walls of the onion epidermis are relatively thick (Suslov et al. 2009). Therefore, the wall behavior upon pressurization was well-reproduced using wedges, which have some bending stiffness 
(Routier-Kierzkowska et al. 2012), rather than membrane elements alone (Bozorg et al. 2014; Weber et al. 2015; Mosca et al. 2017).

Our empirical and model results show that the mechanical behavior of a simple-morphology tissue such as a cell monolayer can be counterintuitive. When the cells lose turgor pressure and their periclinal cell walls shrink, the strips expand in width rather than contracting. This behavior is caused by the anisotropy in cell shape. Upon pressurization, the periclinal walls bulge out, pulling the anticlinal walls and also the tissue margins closer (the air-mattress effect). Shrinking upon inflation has been shown to be involved in the turgordriven shrinkage of valve epidermis in siliques of Cardamine hirsuta, which results in explosive seed dispersal (Hofhuis et al. 2016). The anisotropy of the monolayer strain depends on the geometry of cells and mechanical properties of their walls. In onion epidermis the cells are elongated, and thus the changing pressure (pressurization or pressure loss) leads to higher tissue strain in the transverse direction than in the longitudinal direction. The transverse strain is likely further facilitated by a generally zig-zag arrangement of anticlinal walls at cell tips. Such a network of anticlinal walls is easy to stretch or compress in the transverse direction. The specific tissue morphology is complemented by the anisotropic hoop (transverse) reinforcement of periclinal walls. Thus, strain in the longitudinal direction is opposite to that in the transverse direction (e.g., upon the loss of turgor pressure the tissue extends in the transverse direction and shrinks in a longitudinal direction). An important conclusion from our model is that the net microfibril orientation is important for this strain anisotropy, not the orientation of microfibrils in the protoplast-facing layer (the youngest wall layers). This implies that the anisotropy of older wall layers has a significant effect on the load-bearing properties of the wall. It is nevertheless possible that in walls of growing cells the youngest layers are more important. It is also possible that in the epidermis of mature onions examined here, the youngest wall layers were deposited after the cessation of growth. If so, the orientation of microfibrils in these layers was not affected by the anisotropic expansion of the wall (Suslov et al. 2009) and the wall reinforcement by microfibrils was not "dedicated" to affect growth anisotropy. This could explain why the microfibril orientation in the youngest wall layers was not uniform, and why the microfibrils orientation in these layers is oblique, unlike the net orientation observed across all of the older layers.

The interdependence between cells and the tissue can be seen by the influence the tissue has on individual cell behavior. Our model shows that upon pressurization the shape of thin elongated cells located at tissue margins is approximately cylindrical, as in isolated cells, whereas the shapes of similarly elongated cells embedded in the tissue are more complex; the curvature of periclinal walls is not uniform and tends to be affected by adjoining wall junctions. The local strain of periclinal walls upon pressurization seems to depend on the distance from the anticlinal walls and the three-way wall junctions. This effect is pronounced in relatively wide and short cells: the wall strain is less anisotropic further away from wall junctions and anticlinal walls, as if the influence of neighboring cells decreased with the distance, and locally the cell walls behaved like isolated spheres (isotropic wall strain). Additionally, the anticlinal walls are relatively flat, as the turgor pressure on both sides is the same. This allows the tissue to shrink more in width when pressurized compared to an isolated cell, which would also bulge out at the sides.

The distance from the anticlinal walls and wall junctions also affects the pattern of wrinkles formed in the onion epidermis on the youngest layer of periclinal cell walls upon the loss of turgor pressure. The wrinkling is a manifestation of buckling of the youngest wall layers after the tensile in-plane stress is removed from the wall (Hejnowicz and Borowska-Wykręt 2005; Lipowczan et al. 2018). Buckling results from a gradient in elastic strain of the wall layers, likely caused by a gradient of pre-stress and (or) Young's modulus. In the epidermis of cylindrically shaped organs like coleoptiles or etiolated hypocotyls, the removal of in-plane wall stress leads to the formation of a regular pattern of transverse wrinkles, unlike the wrinkle pattern in onion epidermis. In these tissues, however, the in-plane wall stress originates from both turgor and tissue stresses, and upon removal of the stress, the periclinal wall strain is much stronger than in onion, and more anisotropic, with the maximal shrinking in the longitudinal direction. Consequently, the wrinkles are transverse, i.e., orthogonal to the direction of maximal wall shrinking. The epidermal cells in hypocotyls or coleoptiles are also more elongated and have tips that are less pointed than in onion. These differences in the wall strain and cell shape are likely the reason that the wrinkle pattern in onion is more complex. The pattern tends to depend not only on the wall strain (direction of the maximal shrinking), but also on the location within the cell walls and local wall curvature. Wrinkles on the cylindrically shaped central portion of periclinal wall are nearly longitudinal. If the cells were isolated cylinders, such orientation would be perpendicular to the direction of maximal wall stretch in the turgid state (Hejnowicz 2011), and thus the expected direction of maximal shrinking. The observed polylamellate microfibril arrangement in the youngest wall layers would not disable shrinking in the transverse direction. However, simulations of local strain showed that such a deformation (transverse shrinking upon stress removal) is only to be expected in the wall portions that are located far from the wall junctions. It is thus likely that in cylindrically shaped portions of walls in which the maximal strain 
direction is nearly longitudinal, the wrinkle orientation is mainly affected by the wall curvature or the curvature changes upon the removal of stress. On the other hand, wrinkles formed near the periclinal wall margins are always nearly transverse to the neighboring anticlinal walls. This orientation is likely normal to the direction of the maximal wall shrinking. Our simulations show that the strain of periclinal wall margins located along the relatively long anticlinal walls is strongly anisotropic, with maximal strain along the anticlinal walls. Although it has not been included in the model, data in the literature suggest that in the onion epidermis, the anticlinal walls may shrink more than the periclinal walls. The anticlinal walls are double walls (walls of adjacent cells glued by a middle lamella), but they are thinner than outer periclinal walls (Suslov et al. 2009), and their modulus is most likely lower, because they lack cuticle. The epidermal surface over the anticlinal walls is covered by a gusset of relatively soft material (visible as a thin ribbon along the cell outlines in the SEM micrographs; Figs. 2 and 3) that likely locally protects the surface (Routier-Kierzkowska et al. 2012), but does not prevent locally increased shrinking at the periclinal wall margins.

\section{Conclusions}

In onion epidermis, the surface strain upon osmotic treatment is small because the outer periclinal walls are relatively thick and stiff. The wall behavior is thus better reproduced by an FEM model using volumetric elements that give the material some bending stiffness, rather than membrane elements. Shell elements are another possibility. The empirical assessment of onion epidermis deformation upon the loss of turgor pressure complemented by a mechanical model, facilitates the exploration of the interdependence of cellular geometry and the mechanical behavior of the tissue and walls of its component cells. Upon changes in internal pressure, the onion epidermal cells embedded in the monolayer, a simply organized tissue, undergo deformation that is very different from deformation of isolated cells of a similar shape. The cell monolayer, in turn, undergoes a counterintuitive deformation upon the pressure changes (e.g., shrinking upon inflation) that depends on the geometry of component cells.

At the tissue scale, the strain of onion epidermis upon the loss of turgor pressure is strongly anisotropic (transverse extension and longitudinal shrinkage), while the periclinal cell walls shrink in both of the principal directions. The strain anisotropy varies within walls of individual cells, and is affected by the shape of the cell and vicinity of three-way junctions of anticlinal walls. As the wall strain in onion is small and not strongly anisotropic, the pattern of wrinkles formed due to buckling on the protoplast-facing wall surface depends not only on the strain anisotropy, but also on the local geometry of the wall, unlike in epidermis of cylindrically shaped organs in which the tissue stresses operate.

\section{Acknowledgements}

This work was supported by the National Science Centre, Poland, research grant MAESTRO No. 2011/02/A/NZ3/ 00079 to D.K.; ERA-CAPS project V-Morph to D.K. (National Science Centre, Poland, grant No 2017/24/Z/ NZ3/00548) and R.S.S. (German Research Foundation DFG project number 355722357); the Max Planck Institute for Plant Breeding Research core funding to R.S.S.; and the University of Zürich Forschungskredit to G.M. We thank Ewa Teper (Laboratory of Scanning Electron Microscopy, Faculty of Earth Sciences, University of Silesia) for the help with preparing the SEM micrographs; and Dr. Aleksandra Rypień (Faculty of Biology and Environment Protection, University of Silesia) for help with the confocal microscopy. We thank Brendan Lane for the modelling software.

\section{References}

Bassel, G.W., Stamm, P., Mosca, G., de Reuille, P.B., Gibbs, D.J., Winter, R., et al. 2014. Mechanical constraints imposed by 3D cellular geometry and arrangement modulate growth patterns in the Arabidopsis embryo. Proc. Natl. Acad. Sci. U.S.A. 111(23): 8685-8690. doi:10.1073/pnas.1404616111. PMID: 24912195.

Berens, P. 2009. CircStat: a MATLAB toolbox for circular statistics. J. Stat. Softw. 31(10): 1-21. doi:10.18637/jss.v031.i10.

Borowska-Wykręt, D., Rypień, A., Dulski, M., Grelowski, M., Wrzalik, R., and Kwiatkowska, D. 2017. Gradient of structural traits drives hygroscopic movements of scarious bracts surrounding Helichrysum bracteatum capitulum. Ann. Bot. 119(8): 1365-1383. doi:10.1093/aob/mcx015. PMID:28334385.

Boudaoud, A., Burian, A., Borowska-Wykręt, D., Uyttewaal, M., Wrzalik, R., Kwiatkowska, D., and Hamant, O. 2014. FibrilTool, an ImageJ plug-in to quantify fibrillar structures in raw microscopy images. Nat. Protoc. 9(2): 457-463. doi:10.1038/ nprot.2014.024. PMID:24481272.

Bozorg, B., Krupinski, P., and Jönsson, H. 2014. Stress and strain provide positional and directional cues in development. PLoS Comput. Biol. 10(1): e1003410. doi:10.1371/journal.pcbi.1003410. PMID:24415926.

de Reuille, P.B., Routier-Kierzkowska, A.L., Kierzkowski, D., Bassel, G.W., Schüpbach, T., Tauriello, G., et al. 2015. MorphoGraphX: a platform for quantifying morphogenesis in 4D. Elife, 4: e05864. doi:10.7554/eLife.05864.

Dumais, J., and Kwiatkowska, D. 2002. Analysis of surface growth in shoot apices. Plant J. 31(2): 229-241. doi:10.1046/j. 1365-313X.2001.01350.x. PMID:12121452.

Goldfeather, J., and Interrante, V. 2004. A novel cubic-order algorithm for approximating principal direction vectors. ACM Trans. Graph. (TOG), 23(1): 45-63. doi:10.1145/966131. 966134.

Hamant, O., Das, P., and Burian, A. 2014. Time-lapse imaging of developing meristems using confocal laser scanning microscope. In Plant cell morphogenesis. Methods in molecular biology (methods and protocols). Edited by V. Žárský and F. Cvrčková. Humana Press, Totowa, N.J. pp. 111-119.

Hejnowicz, Z. 2011. Plants as mechano-osmotic transducers. In Mechanical integration of plant cells and plants. Signaling and communication in plants. Edited by P. Wojtaszek. Springer, Berlin, Germany. pp. 241-267.

Hejnowicz, Z., and Borowska-Wykręt, D. 2005. Buckling of in- 
ner cell wall layers after manipulations to reduce tensile stress: observations and interpretations for stress transmission. Planta, 220(3): 465-473. doi:10.1007/s00425-004-1353-z. PMID:15365835.

Hofhuis, H., Moulton, D., Lessinnes, T., Routier-Kierzkowska, A.L., Bomphrey, R.J., Mosca, G., et al. 2016. Morphomechanical innovation drives explosive seed dispersal. Cell, 166(1): 222-233. doi:10.1016/j.cell.2016.05.002. PMID:27264605.

Kerstens, S., Decraemer, W.F., and Verbelen, J.P. 2001. Cell walls at the plant surface behave mechanically like fiberreinforced composite materials. Plant Physiol. 127(2): 381385. doi:10.1104/pp.010423. PMID:11598213.

Kierzkowski, D., Nakayama, N., Routier-Kierzkowska, A.L., Weber, A., Bayer, E., Schorderet, M., et al. 2012. Elastic domains regulate growth and organogenesis in the plant shoot apical meristem. Science, 335(6072): 1096-1099. doi:10.1126/ science.1213100. PMID:22383847.

Kwiatkowska, D., and Burian, A. 2014. Sequential replicas for in vivo imaging of growing organ surfaces. In Plant cell morphogenesis. Methods in molecular biology (methods and protocols). Edited by V. Žárský and F. Cvrčková. Humana Press, Totowa, N.J. pp. 99-110.

Leney, L. 1981. A technique for measuring fibril angle using polarized light. Wood Fiber Sci. 13(1): 13-16.

Lipowczan, M., Borowska-Wykręt, D., Natonik-Białoń, S., and Kwiatkowska, D. 2018. Growing cell walls show a gradient of elastic strain across their layers. J. Exp. Bot. 69(18): 43494362. doi:10.1093/jxb/ery237. PMID:29945239.

Mosca, G., Sapala, A., Strauss, S., Routier-Kierzkowska, A.L., and Smith, R.S. 2017. On the micro-indentation of plant cells in a tissue context. Phys. Biol. 14(1): 015003. doi:10.1088/1478-3975/ aa5698. PMID:28181475.

Ng, A., Parker, M.L., Parr, A.J., Saunders, P.K., Smith, A.C., and Waldron, K.W. 2000. Physicochemical characteristics of onion (Allium cepa L.) tissues. J. Agric. Food Chem. 48(11): 56125617. doi:10.1021/jf991206q. PMID:11087527.

Oparka, K.J. 1994. Plasmolysis: new insights into an old process. New Phytol. 126(4): 571-591. doi:10.1111/j.1469-8137.1994. tb02952.x.

Routier-Kierzkowska, A.L., and Kwiatkowska, D. 2008. New stereoscopic reconstruction protocol for scanning electron microscope images and its application to in vivo replicas of the shoot apical meristem. Funct. Plant Biol. 35(10): 1034-1046. doi:10.1071/FP08047.

Routier-Kierzkowska, A.L., Weber, A., Kochova, P., Felekis, D., Nelson, B., Kuhlemeier, C., and Smith, R.S. 2012. Cellular force microscopy for in vivo measurements of plant tissue mechanics. Plant Physiol. 158(4): 1514-1522. doi:10.1104/pp. 111.191460. PMID:22353572.

Sapala, A., Runions, A., Routier-Kierzkowska, A.L., Gupta, M.D., Hong, L., Hofhuis, H., et al. 2018. Why plants make puzzle cells, and how their shape emerges. Elife, 7: e32794. doi:10. 7554/eLife.32794. PMID:29482719.

Shewchuk, J.R. 1996. Triangle: Engineering a 2D quality mesh generator and Delaunay triangulator. In Applied computational geometry towards geometric engineering. WACG 1996. Lecture Notes in Computer Science 1148. Edited by M.C. Lin and D. Manocha. Springer, Berlin, Germany. pp. 203-222.

Suslov, D., Verbelen, J.P., and Vissenberg, K. 2009. Onion epidermis as a new model to study the control of growth anisotropy in higher plants. J. Exp. Bot. 60(14): 4175-4187. doi:10. 1093/jxb/erp251. PMID:19684107.

Vanstreels, E., Alamar, M.C., Verlinden, B.E., Enninghorst, A., Loodts, J.K.A., Tijskens, E., Ramon, H., and Nicolaï, B.M. 2005. Micromechanical behaviour of onion epidermal tissue. Postharvest Biol. Technol. 37: 163-173. doi:10.1016/j.postharvbio. 2005.04.004.

Weber, A., Braybrook, S., Huflejt, M., Mosca, G., Routier-Kierzkowska, A.L., and Smith, R.S. 2015. Measuring the mechanical properties of plant cells by combining microindentation with osmotic treatments. J. Exp. Bot. 66(11): 3229-3241. doi:10.1093/jxb/erv135. PMID:25873663.

Wei, C., Lintilhac, P.M., and Tanguay, J.J. 2001. An insight into cell elasticity and load-bearing ability. Measurement and theory. Plant Physiol. 126(3): 1129-1138. doi:10.1104/pp.126.3. 1129. PMID:11457963.

Zamil, M.S., Yi, H., Haque, M.A., and Puri, V.M. 2013. Characterizing microscale biological samples under tensile loading: stress-strain behavior of cell wall fragment of onion outer epidermis. Am. J. Bot. 100(6): 1105-1115. doi:10.3732/ajb. 1200649. PMID:23720433.

Zar, J.H. 1999. Biostatistical analysis. Pearson Education, Tamil Nadu, India.

Zhang, T., Mahgsoudy-Louyeh, S., Tittmann, B., and Cosgrove, D.J. 2014. Visualization of the nanoscale pattern of recently-deposited cellulose microfibrils and matrix materials in never-dried primary walls of the onion epidermis. Cellulose, 21(2): 853-862. doi:10.1007/s10570-013-9996-1.

Zimmermann, U. 1978. Physics of turgor- and osmoregulation. Annu. Rev. Plant Physiol. 29(1): 121-148. doi:10.1146/annurev. pp.29.060178.001005. 